\title{
Educative Sensemaking on Social Media: An Empirical Investigation of Informal Learning on YouTube
}

\author{
Zixing Shen \\ New Mexico State University \\ zshen@nmsu.edu \\ Songxin Tan \\ South Dakota State University \\ songxin.tan@sdstate.edu
}

\author{
Michael J. Pritchard \\ Kansas State University - Polytechnic \\ mjp001@ksu.edu \\ Cherie Noteboom \\ Dakota State University \\ cherie.noteboom@dsu.edu
}

\begin{abstract}
Educational videos on social media are widely used in informal learning. However, empirical studies hardly look into sensemaking, a key aspect in the construction of meaning and knowledge, of educational videos on social media in informal learning, despite the growing interest and practice in educative sensemaking. This study addresses this research gap. We draw upon sensemaking theories and investigate how the physical properties of educational videos affect sensemaking. Our research shows how information control, anchor, and noise are associated with committed interpretation in the learning communities to understand the scientific inquiry at hand with data from YouTube educational videos. This study makes timely contributions to the literature on the educative sensemaking in informal learning on social media. It also offers insights into the better design of educational videos to facilitate sensemaking and informal learning.
\end{abstract}

\section{Introduction}

Social media provide a tremendous amount of learning resources and the autonomy and control of what and how to learn [12]. As such, they open up new opportunities for informal learning, learning that occurs away from the traditional instructor-led structured educational system. Informal learning on social media comes in many forms, including viewing videos, participating in forums and chat rooms, and playing games. This study focuses on educational videos on social media.

Educational videos on social media have been increasingly popular, thanks to the explosive growth and massive success of video-sharing websites like
YouTube and the affordance of mobile phones to record, disseminate and access videos in the last 15 years or so. The vast number of videos with educational purposes (e.g., scientific explanation of a phenomenon, demonstration of an expert procedure) available on YouTube offers unprecedented informal learning opportunities. YouTube has arguably become a viable venue for informal learning.

Not surprisingly, YouTube educational videos have been extensively researched. Extant studies have examined video quality [1], user acceptance [18], the effectiveness of self-directed learning [19], and its use for school-age children [8]. They also have probed into the effects of YouTube educational videos on learning, such as learner satisfaction [12] and perceived learning [36]. Yet, research on the sensemaking of YouTube educational videos is very limited, considering the increasing interest and practice in educative sensemaking [9].

In this paper, we approach informal learning on YouTube from the sensemaking perspective. Sensemaking is chiefly concerned with how individuals make sense of complex and dynamic phenomena, construct mental representations of these phenomena, and use these representations to guide their actions. In contrast to the more normative decision-making perspective that focuses on one-time decisions, sensemaking is about organizing the chaos of lived experiences, finding patterns, discovering connections and dependencies, and making choices regarding essential self-management activities [21]. We view learning as an act of sensemaking, constructed cognitively and socially. In informal learning on social media, sensemaking focuses on the community of learners. It involves how members of these learning communities create and share knowledge structures and build meaning together. 
Drawing upon sensemaking theories, we investigate how the physical properties of educational videos affect sensemaking in informal learning on YouTube.

In the following sections, we review the related literature on sensemaking and describe our conceptualization of sensemaking of educational videos on social media. Next, we present our research constructs and hypotheses. We then detail the research method, including data collection and measurement, and report our findings. Finally, we discuss our research findings, research contributions, practical implications, limitations and future research, and conclude the paper.

\section{Related work}

\subsection{Sensemaking theories}

Sensemaking has diverse theoretical routes and has been explored in a wide variety of domains and disciplines. Four perspectives on sensemaking have become very influential: cost structure of sensemaking [30], the data/frame theory [17], individual sensemaking [6], and collective sensemaking [41].

Russell and colleagues were among the first to introduce sensemaking into the Human-Computer Interaction (HCI) community [32] by examining the efforts of expert analysts when creating a formal knowledge representation of a particular domain. In this tradition, sensemaking is defined as "the way people go about their process of collecting, organizing and creating representations of complex information sets, all centered around some problem they need to understand." [32]. It is about how humans identify representations for complex information tasks, encode data into these representations, and iteratively modify those representations to minimize cognitive effort and maximize task solution effectiveness. As such, sensemaking involves the interplays between foraging for information and abstracting the information into a representation.

The data/frame theory centers around the concept of the frame (mental model) [16]. Frames reflect a person's compiled experiences and can be expressed in various forms, including stories, maps, organizational diagrams, or scripts. They are explanatory structures that account for data and guide the search for more data. Frames can be elaborated (e.g., filling in details), questioned (e.g., due to the detection of anomalies), or reframed (e.g., rejecting a frame and replacing it with another). Sensemaking is a process of framing and reframing, fitting data into a frame that helps filter and interpret data while testing and improving the frame and cyclically moving forward to further adapt the frame.
Dervin and Naumer [6] use sensemaking to explain how information is understood and used by individuals. In this methodology, sensemaking occurs when a person is embedded in a particular context, and moving through time-space, experiences a gap in reality. To encounter this gap, the person forms ideas, thoughts, emotions, feelings, and memories. Dervin's sensemaking methodology has been popular in communication and information science studies, focusing on the individual.

Weick's sensemaking theory explains how people work together to interpret, give meaning to, and create a collective sense of the work they do [38]. Sensemaking is a social process grounded in identity construction, retrospective, focused on and by extracted cues, ongoing, enactive of sensible environments, and driven by plausibility rather than accuracy [39]. Collective sensemaking is common, as tasks need a rapid response that integrates multiple sources of information (such as on-the-scene disaster response) or are so complicated and dynamic that they require sharing information, intents, interpretation among different people and groups (such as strategic organizational changes). Weick's collective sensemaking theory is widely used in management and organizational behavior research.

Figure 1 locates the four sensemaking perspectives on the dimensions of the unit of analysis (individual vs. collective) and the application focus (internalized vs. externalized). Weick focuses on social activity (collective), and sensemaking is internalized as reflected in collective meaning. Dervin adopts a hermeneutic approach to the individual's situation, and sensemaking is internalized as the subjective experience. Klein centers on the individual mental model applied to an external context or activity. Russell views sensemaking as a collective effort, mainly in the service of representing external data.

\section{Figure 1. Sensemaking theories}

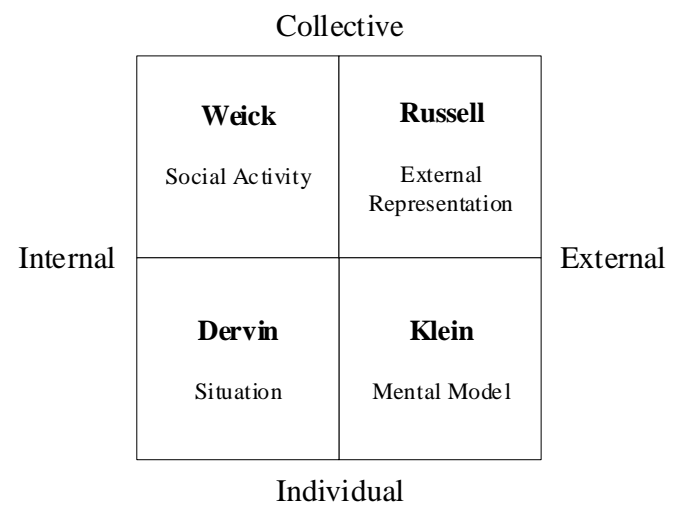


These sensemaking perspectives share three salient characteristics. First and foremost, sensemaking is about meaning generation and understanding construction. Second, sensemaking entails the active processing of information, ranging from collecting, organizing to assigning meaning to information. Third, sensemaking resolves a gap or inadequacy, resulted from information ambiguity and equivocality, in one's understanding.

\subsection{Sensemaking in education}

The sensemaking perspective in education started in math and science education (e.g., [31]) and has now been adopted in many academic disciplines, including literature and history [9]. While traditional scientific education favors logical, hypothetic deductive reasoning in which individuals search through a space of available alternatives until a hypothesis is formulated and attempt to validate it with experimentation [11], proponents of the sensemaking perspective (e.g., [10]) argue that learning is inherently cognitive as well as social. The social cognition approach conceives education learning as an essentially constructive activity instead of an absorptive one. The production of scientific knowledge is a collective endeavor and results from interactions among disciplinary peers [20].

Sensemaking in formal education is defined as a dynamic process of building or revising an explanation to resolve a gap or inconsistency in one's understanding [24]. In the process of sensemaking, learners play the role of constructors, developing their personal understanding. They then become critics of knowledge claims within the learning communities and progress in constructing collective understanding resulted from social interactions with disciplinary peers. The two roles of knowledge creator and critics are intertwined as learners engage in sensemaking.

\subsection{Educative sensemaking on social media}

We adapt the sensemaking perspective in formal education to informal learning with videos on social media based on the sensemaking theories. We conceptualize that educative sensemaking on social media is a two-step process involving interaction with the artifact of the educational video and socialization with fellow learners. In light of the work by Russell and colleagues [30] [26], individual learners first interact with the educational video to collect, organize and create representations of complex information sets in education videos and form their own internal interpretation (developing personal understanding).
This step is primarily cognitive as learners individually try to figure out the video content. Learners are exposed to three types of cognitive load that compete for their limited cognitive capacity available in a specific learning situation. They are intrinsic, extraneous, and germane cognitive load [34]. Intrinsic load is related to the difficulty of the subject under study (i.e., the learning content). Extraneous load is evoked by the learning material but does not directly contribute to learning. Germane load is the level of cognitive activity necessary to reach the desired learning outcome imposed by learning processes. Videos can be designed to carefully structure intrinsic load, minimize extraneous load, and optimize germane load to support sensemaking.

Next, individual learners share their representation and actively participate in the generation of collective understanding with their fellow learners (critiquing understanding). This step is inherently social, in which learners externalize knowing already in their minds (what is known) and explore and analyze new ideas presented by peer learners (what is to be known). In socializing with others, learners compare and contrast their thinking, consider different viewpoints, and negotiate meaningconstruction [39]. Knowing emerges from the meaning construction and reconstruction by involved learners and the learning community's agreement upon the nature of the learning topic. As such, the socialization process enables frame and reframe [16], ultimately resolving the gap or inconsistency in their understanding [6]. YouTube provides opportunities for learners to communicate, interact and socialize.

While earlier research examines learner factors such as pre-existing knowledge of content, learning goal, learner ability [29] [14] in educative sensemaking, this study focuses on the role of technology as sensemaking in the virtual space can be shaped by technology-related factors like the technology's affordance [4] and information visualization [2]. We are particularly interested in how the physical properties of YouTube videos affect sensemaking in informal learning. In the next section, we first describe how sensemaking can be enacted on social media, detail the video physical properties and how they can shape individual learners' interactions with the video and influence their socialization with their peers.

\section{Constructs and hypotheses}

\subsection{Committed interpretation}

Sensemaking can take many forms and work in many ways. On social media, sensemaking is enacted 
via discourse [26] [33]. This paper uses one type of discourse sensemaking - committed interpretation [37]. The concept of committed interpretation involves interpretation and commitment. Interpretation is an integral component of sensemaking because people need to understand and give meaning to the information they hold. For their explicit interpretations to be understood, accepted, and implemented, people need to communicate and interact with others, whether those others are present in the moment or not. They take actions to inspect, interpret, and interact (e.g., asking questions, inserting probes, providing answers, and exchanging ideas). Social media offer individuals the opportunities not available in traditional interactions for self-expression and sharing their understanding, negotiating their opinions, and collectively constructing a discourse reflecting their shared knowledge on the topic of interest.

Furthermore, actions in the social process are public, irrevocable, and, therefore, create commitment. In social media, each individual's action is visible to anyone for an indefinite time. As every action and interaction is hard to undo and disown, social media provide conditions that serve as catalysts for turning such actions and interactions into commitments.

Committed interpretation is demonstrated empirically to be valuable in tracking individuals, as they try to make sense, engage others in social exchanges that become collective sensemaking processes in a digital environment. For example, Nagar [23] uses the concept of committed interpretation in his qualitative inquiry into Wikipedia discussion pages and illustrates how interpretations are negotiated and then committed through conversation in the sensemaking of the Wikipedia policies by its members.

\subsection{Information control}

Sensemaking encompasses the entire gamut of behavior surrounding collecting and organizing information for deeper understanding [27]. The amount of information learners is exposed to can directly impact cognitive loads and thus sensemaking. Segmentation and user control can be used to control the information load in the learning materials.

Segmentation breaks the learning materials into smaller pieces to help learners process one cluster of related information before moving to the next [22]. It can be achieved by dividing the video into shorter segments [13]. User control gives learners control over the flow of the learning materials and enables them to choose how they interact with the learning material [5]. YouTube supports the playback function, which allows the viewers to pause the video at any time point to focus on or review specific segments of the video or jump to a different point in time.

As it divides the learning content into more intellectually manageable chunks, segmentation lowers the video content's intrinsic load. Segmentation makes it is easier to follow the content, facilitating sensemaking. It can also limit the incoming data, minimizing the need to switch back and forth between different data constantly. By supporting maintain learners' attention to the information on the video, segmentation assists the active processing of data, stimulates interpretation and achieves understanding. In addition, learner control enables learners to skip certain parts they already understand and jump to another part they want to work on more. As it provides more time for processing and consolidating the learner-perceived important information, user control supports the cognitive needs in sensemaking. Therefore, we propose:

Hypothesis 1: Information control is positively associated with committed interpretation.

\subsection{Anchor}

Sensemaking builds on extracted cues that individuals apprehend from sense and perception [38]. Sensemaking of videos can be improved if cueing is given to learners for the learning content. Klein and colleagues [17] suggest using anchors (indicators) to see pertinent patterns and connections in the data stream. Anchors are the few key data elements that learners use to construct the explanatory structure (i.e., a frame) that guides collecting data and organizing information. They allow discarding irrelevant data, direct learners' attention to critical elements, and direct information seeking. By guiding learners' attention to the critical information on the screen, anchors can simplify decisions that learners may have to make about which information is relevant. In other words, anchors can lower incidental processing (extraneous load) and promote essential processing (germane load), thus enabling learners to allocate more mental efforts to sensemaking.

In addition, anchors can assist learners in understanding the connections in the elements of the learning material, organizing such understandings into the evolving mental model, and building a coherent and integrated representation of the content of learning [28]. In other words, anchors can support germane load in sensemaking by indicating links between related elements and help learners in building an integrated mental representation. By facilitating selecting key elements and guiding the attention to essential information, anchors can induce more 
behaviors surrounding collecting, organizing, understanding, and integrating information. Thus, we posit:

Hypothesis 2: Anchor is positively associated with committed interpretation.

\subsection{Noise}

As stated earlier, educative sensemaking on social media involves receiving information from educational videos. Therefore, it is subject to noise, a concept similar to the idea of chaos that evokes the experience of disorder, interruption, and irregularity in the organizational context [39]. From the communication perspective, we define noise as any form of interference that affects understanding the message and information in the video.

The video contains a lot of sensory input, not all of which may be relevant and necessary in understanding the video content. For example, the loudness of the video may be distracting as it may require learners to judge whether they should be paying attention to it, particularly when it's either too low or too high [35]. Video resolution may also divert attention, especially when its value is low [35]. The irrelevant and unnecessary information in the video is the noise. The noise does not pertain to the content to be conveyed and causes initial uncertainty about and distracts attention from the essential elements. Noise can prime learners for incidental processing and add extraneous load. It can interfere with how learners decode and understand the learning materials, sidetracks the discussion and exchange of ideas, and creates barriers to committed interpretation. Thus, we submit:

Hypothesis 3: Noise is negatively associated with committed interpretation.

Figure 2. Research model

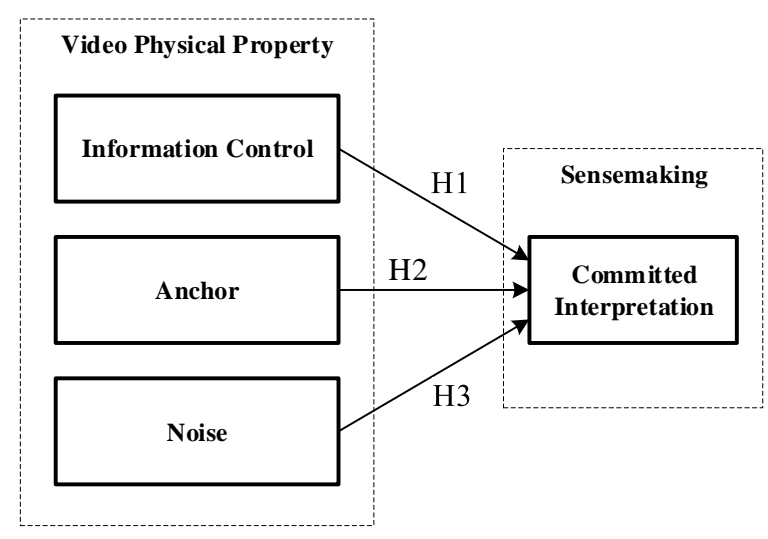

Presented in Figure 2 is the research model that guides our empirical investigation.

\section{Methods}

\subsection{Data collection}

The research model was tested by using educational videos from YouTube. YouTube is regarded as an important platform for informal learning with millions of educational videos on almost any topic (e.g., applying makeup, computer programming). Anyone can create and upload a video to YouTube. YouTube also offers an extensive range of features beyond uploading and viewing video clips. For example, viewers may post comments to a video.

We sampled YouTube videos on 28 topics in physics and astronomy. We used the topic name (e.g., Boltzmann Brain) as a search term and searched the YouTube site. Each search generated a large number of videos, and the first 40 videos in English with an educational focus, rated by the YouTube ranking algorithm, were included for further analysis. Next, each of the 40 videos was assigned a number on the seven-Likert scale (one stands for least popular and seven for most popular) based on its ranking from the YouTube search. We put the top five or six search results to the Likert scale of 7 (most popular), the next five or six to the Likert scale of 6 (more popular), so on and forth, and finally the bottom five or six to the Likert scale of 1 (least popular). Then we randomly picked one video on each Likert scale. Seven videos were chosen for one topic to represent the 40 videos at different points of the popularity spectrum. This process was conducted across all 28 topics. In total, 196 videos (i.e., 28 topics times seven video samples per topic) were included for data analysis. Information on selected videos is available upon request.

\subsection{Measurements}

Information control could be operationalized by segmentation and use control. We used video length to measure segmentation. The usage statistic of the playback function was not available, and as a result, we were not able to measure user control.

We identified two types of anchors - model and mathematical equation. A model is a diagram, graph, or representation that conceptually describes a physical phenomenon. A mathematical equation represents the mathematical relationships between physical concepts. Figure 3 and Figure 4 illustrate the use of model and mathematical equation, respectively. Each video was checked manually for model and 
mathematical equation. A video was coded as 0 if a model was not found and 1 if a model was present. A video was coded as 0 without a mathematical model and 1 otherwise.

Noise was operationalized as loudness and resolution. We used the default decibels to indicate loudness. The YouTube default decibels are measured by decibels relative to full scale (dBFS), where $0 \mathrm{dBFS}$ is the maximum digital signal level.

The YouTube comments allow individual learners to express themselves, ask for specifics and clarification, examine different opinions, seek to resolve conflicting perspectives, and transform the ideas. Research has found that the YouTube comments support sharing and adding information, negotiating and elaborating meaning, and synthesizing and applying knowledge in conceptually rich domains like science [7]. The comment statistic, which provides a tally of comments populated by input from YouTube users, served as a proxy for committed interpretation.

Given that older videos have had a more extended period to accumulate responses, the number of days since posted (the time interval between the posting date of a video and the date of the video was sampled) was used as a control variable. Table 1 summarizes the constructs and their measurements.

Figure 3. Model screenshot

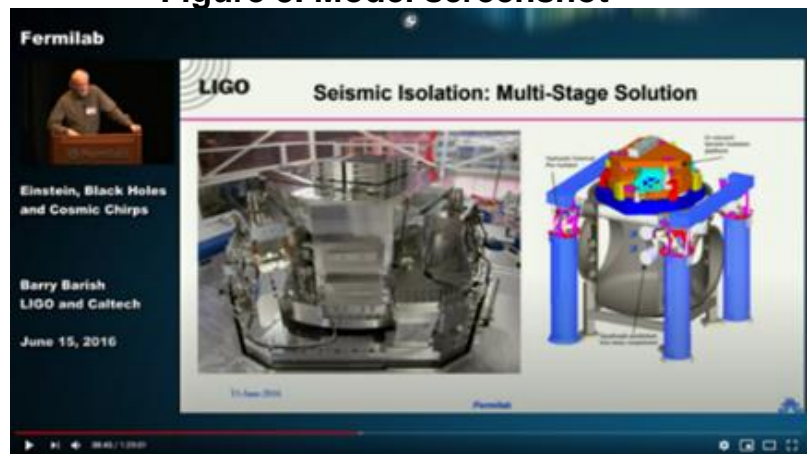

Figure 4. Math equation screenshot

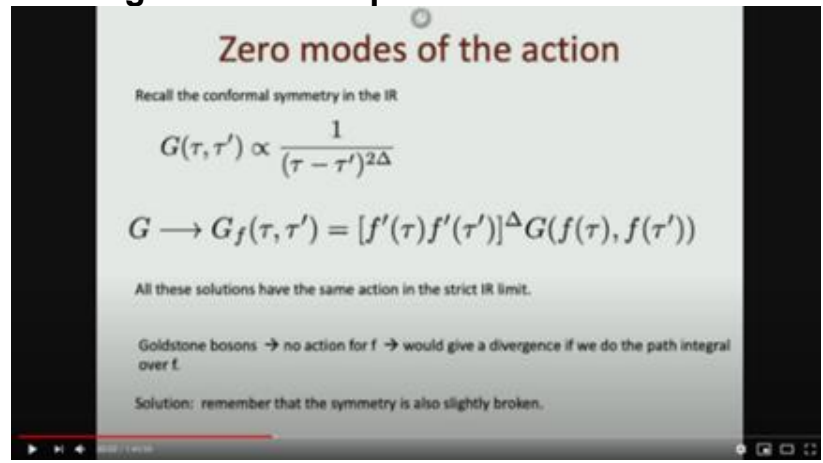

\begin{tabular}{|l|l|l|l|}
\hline \multicolumn{2}{|c|}{ Variable } & Data Type & Source \\
\hline $\begin{array}{l}\text { Committed } \\
\text { Interpretation }\end{array}$ & Comments & discrete & YouTube \\
\hline Segmentation & Video length & continuous & YouTube \\
\hline Anchor & Model & binary & Manual \\
\cline { 2 - 4 } & $\begin{array}{l}\text { Math } \\
\text { equation }\end{array}$ & binary & Manual \\
\hline \multirow{2}{*}{ Noise } & Resolution & continuous & YouTube \\
\cline { 2 - 4 } & Loudness & continuous & YouTube \\
\hline Control & Days posted & discrete & YouTube \\
\hline
\end{tabular}

Table 1. Variable and measurement

\section{Results}

The descriptive statistics of the variables are shown in Table 2.

\begin{tabular}{|c|c|c|c|c|c|}
\hline \multicolumn{2}{|c|}{ Variable } & Mean & S.D. & Max & Min \\
\hline $\begin{array}{l}\text { Committed } \\
\text { Interpretation }\end{array}$ & $\begin{array}{l}\text { YouTube } \\
\text { comments }\end{array}$ & $5,259.40$ & $47,295.13$ & 661,050 & 0 \\
\hline Segmentation & $\begin{array}{l}\text { video } \\
\text { length } \\
\text { (minutes) }\end{array}$ & 26.29 & 29.42 & 116.24 & 0.30 \\
\hline \multirow[t]{2}{*}{ Anchor } & $\begin{array}{l}\text { math } \\
\text { equation }\end{array}$ & 0.29 & 0.453 & 1 & 0 \\
\hline & model & 0.79 & 0.41 & 1 & 0 \\
\hline \multirow[t]{2}{*}{ Noise } & $\begin{array}{l}\text { default } \\
\text { decibel }\end{array}$ & -2.67 & 4.20 & 5.30 & -21.70 \\
\hline & $\begin{array}{l}\text { resolution } \\
\text { (pixel) }\end{array}$ & 1180.11 & 242.58 & 1280.11 & 240.24 \\
\hline Control & $\begin{array}{l}\text { days } \\
\text { posted }\end{array}$ & 1093.27 & 810.68 & 4420 & 48 \\
\hline
\end{tabular}

Table 2. Descriptive statistics

\begin{tabular}{|c|c|c|}
\hline \multirow[t]{2}{*}{ Variable } & \multicolumn{2}{|c|}{$\begin{array}{l}\text { Committed Interpretation } \\
\text { (YouTube Comments) }\end{array}$} \\
\hline & $\begin{array}{l}\text { Regression } \\
\text { Coefficient }\end{array}$ & p-Value \\
\hline Constant & 4.193 & \\
\hline \multicolumn{3}{|l|}{ Segmentation } \\
\hline Video length & 0.157 & 0.025 \\
\hline \multicolumn{3}{|l|}{ Cue } \\
\hline Math equation & -.061 & 0.375 \\
\hline Model & 0.214 & 0.003 \\
\hline \multicolumn{3}{|l|}{ Noise } \\
\hline Resolution & 0.118 & 0.117 \\
\hline Default decibel & -0.173 & 0.023 \\
\hline \multicolumn{3}{|l|}{ Control } \\
\hline Days posted & 0.001 & 0.991 \\
\hline Adjusted R ${ }^{2}$ & & \\
\hline
\end{tabular}

Table 3. Multiple linear regression analysis

To test our hypotheses, we conducted multiple linear regression analysis. The variance inflating factors (VIF) of all variables were less than two, indicating the absence of multicollinearity. The analysis results are reported in Table 3 . The coefficient of video length is 0.157 , with a p-value of 0.025 , supporting $\mathrm{H} 1 . \mathrm{H} 2$ is partially supported. The model anchor has a coefficient of $0.214(\mathrm{p}=0.003)$, but the 
mathematical equation anchor is not significant. H3 is also partially supported. Loudness has a coefficient of $-0.173(p=0.023)$, whereas resolution is insignificant. The number of days since posted (the control variable) does not have any significant impact, although older videos have a more extended period to accumulate responses.

\section{Discussions}

\subsection{Interpretation of results}

In this study, we proposed and tested the effect of video properties (informal control, anchor, and noise) on sensemaking (committed interpretation) in informal learning on social media. The first major takeaway from our findings is that information control, specifically segmentation, matters. Shorter videos are associated with more committed interpretations.

In addition, the model anchor effectively facilitates the sensemaking of physics and astronomy materials. Contrary to our prediction, the mathematical equation anchor does not have a positive association with sensemaking. Instead, it has a negative, though insignificant, association with sensemaking. A plausible explanation is that learners in our study may lack the mathematical skills to comprehend the blending of physical ideas and mathematical symbolism. Math equation maps a physical phenomenon into a mathematical structure. Learners in this study are primarily general knowledge seekers and may not understand the physical and mathematical structure aspects relevant to the physical phenomenon.

\begin{tabular}{|l|l|l|}
\hline $\begin{array}{l}\text { Video Resolution } \\
\text { (pixel) }\end{array}$ & $\begin{array}{l}\text { \# of Videos } \\
(\%)\end{array}$ & $\begin{array}{l}\text { \# of Comments } \\
(\%)\end{array}$ \\
\hline $240-449$ & 4 & 1,170 \\
& $(2.04 \%)$ & $(0.11 \%)$ \\
\hline $450-659$ & 21 & 4,076 \\
& $(10.71 \%)$ & $(0.40 \%)$ \\
\hline $660-869$ & 3 & 299 \\
& $(1.53 \%)$ & $(0.03 \%)$ \\
\hline $870-1079$ & 4 & 48 \\
& $(2.05 \%)$ & $(0.01 \%)$ \\
\hline $1081-1290$ & 164 & $1,025,250$ \\
& $(83.67 \%)$ & $(99.45 \%)$ \\
\hline
\end{tabular}

Table 4. Statistics by Video Resolution

Finally, the loudness of the video is detrimental to sensemaking. Our study does not find video resolution influences committed interpretation. This may be attributed to the fact that the sampled videos overall have a decent resolution. The comment statistics at five different levels of resolution are listed in Table 4 .
The numbers in the parentheses represent the percentages of videos of all videos in the sample. About $85 \%$ of the videos have a resolution in the top $20 \%$ of the resolution range.

\subsection{Research contributions}

Our study expands the research on YouTube educational videos. Extant research approaches YouTube educational videos mainly from user acceptance and learning outcomes [18] [36]. We use the lens of sensemaking in our investigation. Our research extends educative sensemaking from formal education to informal learning. It sheds new light on sensemaking in informal learning with educational videos on social media.

Moreover, our study contributes to the analysis of sensemaking in the online environment. Online discussions are commonly used to discern learning in online learning literature (e.g., [42]). They are also popular to gauge sensemaking in social medial (e.g., [23] and online communities (e.g., [21]). While online discussions are usually analyzed qualitatively (e.g., content analysis), this study treats them in quantitative terms. Our quantitative approach complements the qualitative analysis and provides a more comprehensive view of educative sensemaking in virtual spaces.

Third, our research advances the knowledge of the technology-related factors that affect sensemaking with educational videos. Our study demonstrates the impacts of the video's physical properties on learner sensemaking. It provides empirical evidence of the positive association between sensemaking and segmentation and anchor and the negative association between sensemaking and noise.

\subsection{Implications for practice}

Sensemaking can be supported by designing certain aspects into technology artifacts [32]. Our study provides YouTube video producers some guidelines in creating videos that facilitate sensemaking. First, make the video shorter if possible. Second, select the appropriate anchors to cue viewers. Mathematical equations can be difficult for amateurs and should be minimized if possible. Third, keep the default decibel low to avoid distraction.

Although this study's findings are based on YouTube educational videos on physics and astronomy in informal learning, they are still relevant to the design of videos in other topics and learning contexts. Therefore, our study is valuable to video producers and instructors towards high-quality production and organization of educational video 
content. Additionally, the importance of sensemaking in video goes beyond learning and education, as videos have made significant inroads into online domains such as digital marketing [3], e-commerce [41]. The findings of this study can be beneficial to businesses and organizations interested in the sensemaking of videos on social media.

\subsection{Limitations and future research}

This research is not without limitations. First, we were not able to measure user control in information control. YouTube supports user control (pausing, playing, fast-forwarding, and rewinding), but we could not capture these statistics. Our measurement of information control (video length), though reliable, may not be complete. The user control aspect should be incorporated in future research to validate our findings on the effects of information control on sensemaking.

Second, our treatment of anchors was not exhaustive. We identified two types of anchors. There may be other types of anchors in the videos we sampled. Videos for other subject areas use different anchors. Furthermore, learning physics and astronomy primarily involves top-down information processing. The information to be attended differs from bottom-up and top-down information processing [40]. It would be interesting for future research to examine the effects of anchors on sensemaking in button-up processing and different subject areas.

Third, our study did not indicate the intensity of anchors and noise. Since our study aimed to investigate the influence of video features on sensemaking, our treatment of anchors and noise, although not showing magnitude, still found significant effects and is considered sufficient for this study. Future research can examine the intensity of anchors and noise. It can also pursue other physical properties of the video. For example, it would be interesting to investigate visual complexity as it may have implications for the sensemaking of visual representations [15]. More research on various features will help gain a more in-depth understanding of sensemaking in the technology-mediated learning environment.

Finally, our findings may not be generalized to other online content and populations. The audience of the educational videos in this study does not represent all learners of YouTube educational videos. The video physical properties that facilitate the sensemaking of enthusiastic amateurs of physics and astronomy in our study may not work for other types of learners (e.g., school-age children). Besides, the study was based on lectures on declarative knowledge (knowing what) and cannot be generalized to procedural knowledge (knowing-how). Whereas declarative knowledge is about factual and conceptual information, procedural knowledge involves memorizing an organized and discrete sequence of behaviors. It is typically presented in tutorials (e.g., a problem-solving walkthrough). The findings from our study on lectures for declarative knowledge may not apply or apply well to tutorials for procedural knowledge. Future research can sample different learner populations and learning materials to examine the differences in the effects of video features on sensemaking on social media.

\section{Conclusion}

This study is the first work we know that has explored sensemaking in educational videos on social media. Our research findings bring to light how the videos' physical properties affect learners' sensemaking in the online informal learning environment. They also inform educational video designers and developers to facilitate sensemaking activities with the appropriate use of video features. A deeper understanding of sensemaking with videos is needed as educational videos on social media have transformed informal learning. The relevance of social media videos goes beyond learning and education as they have also have changed the interaction between institutions and individuals and between businesses and employees fundamentally.

\section{References}

[1] Azer, S. A., Al Grain, H. A., Al Khelaif, R. A., \& AlEshaiw, S.M. (2013). Evaluation of the educational value of YouTube videos about physical examination of the cardiovascular and respiratory systems. Journal of Medical Internet Research, 15 (11), e.241.

[2] Baker, J., Jones, D., \& Burkman, J. (2009). Using visual representations of data to enhance sensemaking in data exploration tasks. Journal of the Association for Information Systems, 10 (7), 533-559.

[3] Beier, M. (2016). Startups' experimental development of digital marketing activities: A case of online videos. In Proceedings of the 14th Interdisciplinary European Conference on Entrepreneurship Research (IECER), September 7-9, 2016, Chur, Switzerland.

[4] Berente, N., Hansen, S., Pike, J. C., \& Bateman, P. J. (2011). Arguing the value of virtual worlds: Patterns of discursive sensemaking of an innovative technology. MIS Quarterly, 35(3), 685-709.

[5] Biard, N., Cojean, S., \& Jamet, E. (2018). Effects of segmentation and pacing on procedural learning by video. Computers in Human Behavior, 89, 411-417.

[6] Dervin, B., \& Naumer, C. M. (2009). Sensemaking. In M. J. Bates \& M. N. Maack (Eds.) Encyclopedia of 
Library and Information Sciences $\left(3^{\text {rd }}\right.$ Ed.). New York: Taylor and Francis.

[7] Dobovi, L., \& Tabak, I. (2020). An empirical analysis of knowledge co-construction in YouTube comments. Computer \& Education, 156, 103939.

[8] Dyosi, N., \& Hattingh, M. (2018). Understanding the extent of and factors involved in the use of YouTube as an informal learning tool by 11- to 13-year-old children. Innovative Technologies and Learning, 11003, 351-361.

[9] Fitzgerald, M. S., \& Palincsar, A. S. (2019). Teaching practices that support student sensemaking across grades and disciplines: A conceptual review. Review of Research in Education, 43(1), 227-248.

[10] Ford, M. J. (2012). A dialogic account of sensemaking in scientific argumentation and reasoning. Cognition and Instruction, 30(3), 207-245.

[11] Godfrey-Smith, P. (2003). Theory and Reality: An Introduction to the Philosophy of Science ( $1^{\text {st }}$ Ed.). Chicago: University of Chicago Press.

[12] Hong, J.-C., Hwang, M.-Y., Szeto, E., Tsai, C.-R., Kuo, Y.-C. \& Hsu, W.-Y. (2016). Internet cognitive failure relevant to self-efficacy, learning interest, and satisfaction with social media learning. Computers in Human Behavior, 55, 214-222.

[13] Ibrahim, M., Antonenko, P. D., Greenwood, C. M., \& Wheeler, D. (2012). Effects of segmenting, signaling, and weeding on learning from educational video. Learning, Media and Technology, 37(3), 220-235.

[14] Jivet, I., Scheffel, M., Schmitz, M., Robbers, S., Specht, M., \& Chsler, H. (2020). From students with love: An empirical study on learner goals, self-regulated learning, and sensemaking of learning analytics in higher education. The Internet and Higher Education, 47, 100758

[15] King, A. J., Lazard, A. J., \& White, S. R. (2020). The influence of visual complexity on initial user impressions: Testing the persuasive model of web design. Behaviour \& Information Technology, 39(5), 497-510.

[16] Klein, G., Moon, B., \& Hoffman, R. R. (2006). Making sense of sensemaking 2: A macrocognitive model. IEEE Intelligent Systems, 21(5), 88-92.

[17] Klein, G., Phillips, J. K., Rall, E. L., \& Peluso, D. A. (2007). A Data-frame theory of sensemaking. In R. R. Hoffman (Ed.), Expertise out of context: Proceedings of the Sixth International Conference on Naturalistic Decision Making (pp. 113-155), New York: Lawrence Erlbaum.

[18] Lee, D. Y., \& Lehto, M. R. (2013). User acceptance of YouTube for procedural learning: An extension of the Technology Acceptance Model. Computers \& Education, 61, 193-208.

[19] Lee, C. S., Osop, H., Goh, D. H., \& Kelni, G. (2017). Making sense of comments on YouTube educational videos: a self-directed learning perspective. Online information review, 41(5), 611-625.

[20] Longino, H. (2002). The Fate of Knowledge. Princeton, NJ: Princeton University Press.

[21] Mamykina, L., Nakikj, D., Elhadad, N. (2015). Collective sensemaking in online health forums. In
Proceedings of the 33rd Annual ACM Conference on Human Factors in Computing Systems (pp. 32173226), April 18-23, 2015, Seoul, Korea.

[22] Mayer, R. (2009). The Cambridge Handbook of Multimedia Learning ( $2^{\text {nd }}$ Ed.). Cambridge, U.K.; New York: Cambridge University Press.

[23] Nagar, Y. (2012). What do you think? The structuring of an online community as a collective-sensemaking process. In Proceedings of the ACM 2012 Conference on Computer Supported Cooperative Work (pp. 393402_, Seattle, WA, USA, February 11-15, 2012.

[24] Odden, T., \& Russ, R. (2017). Defining sensemaking: Bringing clarity to a fragmented theoretical construct. Science Education, 103,187-205

[25] Oh, O., Eom, C.Y., \& Rao, H.R. (2015). Role of social media in social change: An analysis of collective sensemaking during the 2011 Egypt revolution. Information Systems Research, 26(1), 210-223.

[26] Pirolli, P., \& Card, S. K. (2005, May). The sensemaking process and leverage points for analyst technology. In Proceedings of the International Conference on Intelligence Analysis (pp. 6-11), May 2-6, 2005, McLean, VA.

[27] Pirolli, P. \& Russell, D. M. (2011) Introduction to this Special issue on sensemaking, Human-Computer Interaction, 26 (1-2), 1-8.

[28] Pontis, S., \& Blandford, A. (2016). Understanding "Influence": An empirical test of the data-frame theory of sensemaking. Journal of the Association for Information Science and Technology, 67(4), 841-858.

[29] Rimbey, M., \& Kucan, L., (2018). Implementation as a dynamic process: A case study of teacher sensemaking of a cross-content area vocabulary intervention. Journal of Education, 198 (3), 185-201.

[30] Russell, D. M., Stefik, M. J., Pirolli, P. \& Card, S. K. (1993). The cost structure of sensemaking. In Proceedings of the INTERACT'93 and CHI'93 Conference on Human Factors in Computing Systems (pp. 269-276), May 1993, New York, NY.

[31] Schoenfeld, A. H. (1992). Learning to think mathematically: Problem-solving, metacognition, and sensemaking in mathematics. In D. Grouws, (Ed.), Handbook of Research on Mathematics Teaching and Learning (pp. 334-370), Macmillan, NY.

[32] Seidel, S., Kruse, L. C., Székely, N., Gau, M. \& Stieger, D. (2018). Design principles for sensemaking support systems in environmental sustainability transformations, European Journal of Information Systems, 27(2), 221-247,

[33] Stieglitz, S., Mirbabaie, M., \& Milde, M. (2018). Social positions and collective sensemaking in crisis communication. International Journal of HumanComputer Interaction, 34 (4), 328-355.

[34] Sweller, J., Van Merrienboer, J., \& Paas, F. (1998). Cognitive architecture and instructional design. Educational Psychology Review, 10(3), 251-296.

[35] ten Hove, P., \& van der Meij, H. (2015). Like it or not: What characterizes YouTube's more popular instructional videos? Technical Communication, 62 (1), 48-62. 
[36] Wang, H., \& Chen, C. W (2020). Learning English from YouTubers: English learners' self-regulated language learning on YouTube. Innovation in Language Learning and Teaching, 14(4), 333-346.

[37] Weick, K.E. (1993). Sensemaking in organizations: Small structures with large consequences. In J. K. Murnighan, (Ed.) Social Psychology in Organizations: Advances in Theory and Research (10-37), Prentice Hall College Division.

[38] Weick, K. E. (1995). Sensemaking in Organizations. Thousand Oaks, CA: Sage Publications

[39] Weick, K. E., Sutcliffe, K. M., \& Obstfeld, D. (2005). Organizing and the process of sensemaking. Organization Science, 16(4), 409-421.

[40] Yantis, S. \& Egeth, H. E. (1999). On the distinction between visual salience and stimulus-driven attentional capture. Journal of Experimental Psychology: Human Perception and Performance, 25, 661-676.

[41] Zhang, S., Tan, Z., Yu, J., Zhao, Z., Kuang, K., Liu, J., Zhou, J., Yang, H., \& Wu, F. (2020). Poet: Productoriented video captioner for E-commerce. In Proceedings of the 28th ACM International Conference on Multimedia (pp. 1292-1301), October 12-16, 2020 Seattle, WA.

[42] Zhu, E. (2006). Interaction and cognitive engagement: An analysis of four asynchronous online discussions. Instructional Science, 34, 451-480. 